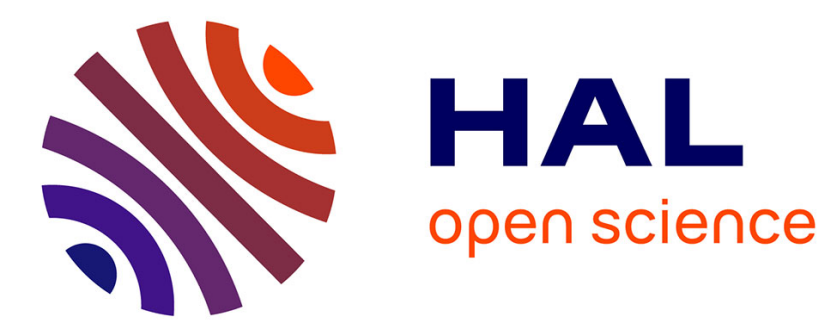

\title{
Design of Portable and Accessible Platform in Charge of Wheelchair Feedback Immersion
}

\author{
Simon Richir, Samuel Pineau, Eric Monacelli, Frédéric Goncalves, Benjamin \\ Malafosse, Claude Dumas, Alain Schmid, Jérôme Perret
}

\section{- To cite this version:}

Simon Richir, Samuel Pineau, Eric Monacelli, Frédéric Goncalves, Benjamin Malafosse, et al.. Design of Portable and Accessible Platform in Charge of Wheelchair Feedback Immersion. IEEE Virtual Reality, Mar 2015, Arles, France. pp.389-390, 10.1109/VR.2015.7223459 . hal-02486129

\section{HAL Id: hal-02486129 \\ https://hal.science/hal-02486129}

Submitted on 20 Feb 2020

HAL is a multi-disciplinary open access archive for the deposit and dissemination of scientific research documents, whether they are published or not. The documents may come from teaching and research institutions in France or abroad, or from public or private research centers.
L'archive ouverte pluridisciplinaire HAL, est destinée au dépôt et à la diffusion de documents scientifiques de niveau recherche, publiés ou non, émanant des établissements d'enseignement et de recherche français ou étrangers, des laboratoires publics ou privés. 


\title{
Design of Portable and Accessible Platform in Charge of Wheelchair Feedback Immersion
}

\author{
Simon Richir ${ }^{1}$, Samuel Pineau ${ }^{2}$, Éric Monacelli ${ }^{2}$, Frédéric Goncalves ${ }^{3}$, Benjamin Malafosse ${ }^{3}$, Claude Dumas ${ }^{3}$, \\ Alain Schmid ${ }^{4}$, Jérôme Perret ${ }^{5}$.
}

${ }^{1}$ Arts et Métiers ParisTech, LAMPA, 2 Bd du Ronceray, 49000 Angers, France ${ }^{2}$ Université de Versailles Saint-Quentin en Yvelines, LISV, 10 avenue de l'Europe, 78140 Vélizy, France ${ }^{3}$ CEREMH, 10 avenue de l'Europe, 78140 Vélizy, France ${ }^{4} E D F$ R\&D, SINETICS / I2C, 1 avenue du Général de Gaulle, 92141 Clamart, France ${ }^{5}$ Haption SA, Atelier Relais ZA Route de Laval, 53210 Soulgé-sur-Ouette, France

\begin{abstract}
Rewarded at Laval Virtual 2014, the AccesSim project aims to develop a wheelchair simulator based on Virtual Reality (VR) and a dynamic force-feedback platform, which allows to experience and to evaluate the accessibility in complex urban or property environment. In order to address this issue, the dynamic forcefeedback platform should provide haptic and vestibular feedback to various user profiles: from town-planners to wheelchair users. The platform needs to be modular and adjustable to each of these profiles. This article focuses on the dynamic force-feedback platform and specifically on the force-feedback systems used.
\end{abstract}

Keywords: virtual reality, handicap, force-feedback.

Index Terms: K.6.1 [Management of Computing and Information Systems]: Project and People Management-Life Cycle; K.7.m [The Computing Profession]: Miscellaneous-Ethics

\section{INTRODUCTION}

The aim of the AccesSim project is threefold. Firstly, it provides tools for experts (architects, town-planners, ergonomists, etc.) to record and diagnose buildings accessibility problems. Secondly, it helps to make people without disabilities aware of the wheelchair mobility issues. Finally, it can also help recently disabled people to drive a wheelchair safely [1]. AccesSim is a VR system composed of a dynamic force-feedback platform coupled with a 3D software simulation. This platform [2] integrates two interaction devices: active rollers and a four-jack motion system. By means of the rollers the platform recreates the behaviour of a powered or manual wheelchair by directly measuring the motion of the wheelchair's active wheels. Therefore, it can generate a torque to assist or block the movement. The four-jack system was chosen to respect the constraints of transportability and accessibility. It is lightweight and the mean working height is relatively low. One of the problems with VR systems is: how to evaluate the realism of the feedback (particularly the vestibular one)? Berthoz \& al. [3] and Grant \& al. [4] demonstrated that driving performance can be affected by the motion scale and gain applied to each motion component. Moreover, Archambault \& al. [5] analysed the wheelchair's motion on a simulator to design a new simulator. Most often, these studies focus on specific experienced drivers (car or plane simulation). In our case, the users represent a broad range of profiles ranging from beginners to active daily wheelchair users. Simulators, useful for novice drivers, improve the manoeuvrability in driving a powered wheelchair [6]. Moreover, Cooper \& al. [7] demonstrate that there is a connection between real life driving ability and performances in a virtual environment. Finally, virtual environments can help to train the user without any risk of

\footnotetext{
* Contact author: simon.richir [a] ensam.eu
}

collision or physical injury (specifically for user with nonvoluntary control movement due to their disability).

\section{THEORY}

\subsection{Force Feedback}

In the AccesSim project, force-feedback is a fundamental dimension of the user experience: the proposition of the project is to let the user feel like a handicapped person in a wheelchair, having to navigate in an unfriendly environment. In particular, the user needs to manage the wheels, by applying realistic forces on them. Those forces shall reflect the current situation (especially slopes, sidewalks, etc.), so that a simple friction is not sufficient. As a consequence, the partners of the project decided to implement a force-feedback system, coupled with a physics engine for simulating real-world situations.

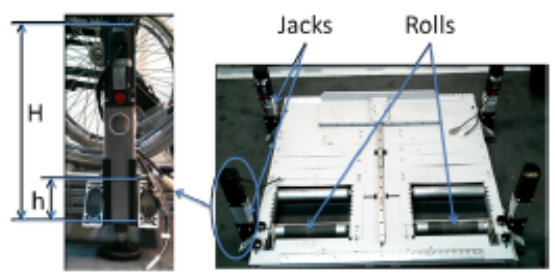

Figure 1. Jack actuator and the platform with rollers and jacks.

\subsection{Performances and Constraints}

In order to be able to present the AccesSim platform during exhibition, conferences or other public even, it is necessary to dismantle, move, assemble and calibrate the platform before each presentation. Also this platform should be accessible for the greatest number of people. Finally, it needs, at least, to reproduce slopes sensation, what make it possible to simulate the actual accessibilities standard. For these purposes, the platform follows three principles: Portability, Mobility and Accessibility. Portability: In order to limit the volume of the platform, its size was fixed: (1) the dimension is limited to $120 \mathrm{x}$ $100 \mathrm{~cm}$, which allows transporting it in a personal car; (2) the weight is limited so that two people could carry it; (3) the time of installation needs to be relatively short. Mobility: To test the accessibility standards, the platform should allow a bend of $6^{\circ}$ (pitch) and $3^{\circ}$ (roll). The platform's reaction time to this slope has to be as fast as possible while being stable and harmless for users. The force-feedback is applied to the real wheelchair's wheels, reflecting the slope and possible collisions with the environment. A short reaction time guarantees a realistic forcefeedback. Accessibility: The AccesSim platform has to be accessible to every person with a motor disability. The installation of a person with motor disability and his/her wheelchair should be fast, secure and harmless (risk-free). In order to achieve that, the platform come down to a low height (10 $\mathrm{cm}$ of the ground), which allows to set up an access ramp 
with a gentle slope $\left(<5^{\circ}\right)$ on a short distance $(1 \mathrm{~m}$ approximately). During this phase, force-feedback rollers are blocked so that the wheelchair can pass over without activating them. Once the wheelchair is in position, the rollers are released. The user can now move in the virtual environment with the help of the force-feedback rollers which will capture the wheel rotation of his/her own wheelchair. However the feedback on rollers will be applied only for a manual wheelchair.

\section{Development}

The created platform is made of aluminium profiles assembled with the help of the screwed modules. Aluminium assures good resistance to mechanic stress and decreases the weight of the system. The platform floor is made of sheet steel to guarantee a rigidity of the surface on which the wheelchair will be positioned.

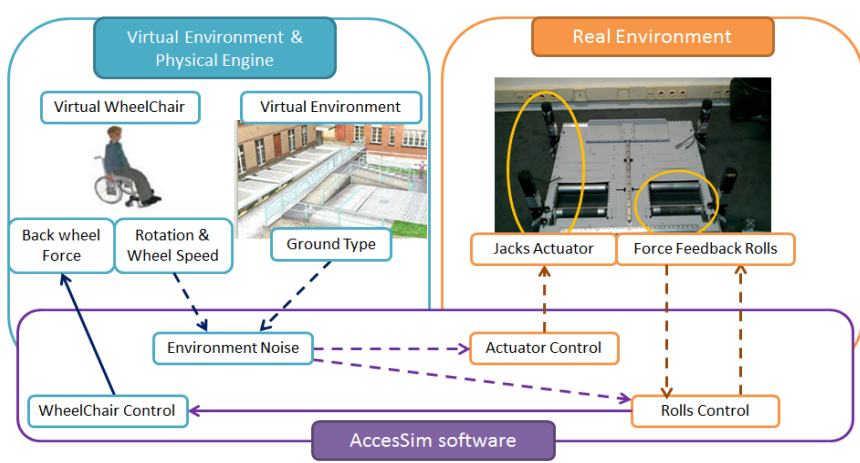

Figure 2. Jack actuator and force feedback roller control command.

\subsection{Platform slope}

The platform slope is ensured by 4 piezoelectric jack actuators situated on both sides of the platform. Jack actuators are positioned at $12 \mathrm{~cm}$ of front and back platform edges, in order to benefit from a $6^{\circ}$ pitch angle (pitch is more important than roll in our case of use). This position also ensures stability of the platform, and consequently the safety of people and equipment. The jack actuators are connected to 3D environment via a control unit. A physics engine is combined to the 3D environment (Fig. 2). It makes the return of the virtual wheelchair movement vary according to the situation: slopes, collisions, ground type. Slopes are directly sent to jack actuator command, while other factors are sent as noise to the jacks in order to increase immersion feeling.

\subsection{Force-feedback rollers}

Force-feedback rollers are made of steel rollers on which real wheelchair's wheels act. During the rotation of the wheel, the roller, by friction, is going to rotate. This rotation is recovered by a belt and delivered to an encoder / brushless motor. Speed, position and force information are recorded through these elements and sent to the control unit. This control unit ensures the communication between the rollers and physics engine which is associated with the 3D environment. Commands from forcefeedback rollers are sent to the virtual wheels as a torque. It is thus possible to control the virtual wheelchair using the real one. At the opposite, virtual environment returns to the control unit different movement conditions: slopes, ground type and collisions. These elements make the force-feedback applied to the rollers, i.e. to the wheels of the real wheelchair. The control unit which is tying roller to 3D environment (Fig 2.) leaves the possibility of working in impedance or admittance mode. On one hand, the impedance law is used to return the issues of rolling (uphill), collisions, and ground type. On the other hand, admittance law is used to accelerate wheelchair's wheels when the user is in downhill, and also recreates the principle of freewheel. Virtual wheelchair commands the real one in this particular case.

\section{Conclusion}

Presented jack actuators and force-feedback rollers provide answers to all issues of portability, mobility and accessibility. Jack actuators are used to increase platform mobility in order to increase user experience, and also help make the platform available to diverse types of wheelchairs. Rollers allow moving virtual wheelchair. At the same time, they send all the movement limits to the software in order to reproduce them in the virtual environment. Through a torque control, it is possible to block rollers during the transport (mobility) or when wheelchair goes up / down on the platform (accessibility). The control unit works in two different modes: impedance and admittance. This mode switching is able to simulate a large number of situations encountered during the motion of the wheelchair: movement in urban area, including up and down the pavement, different ground type and their impact on the bearing, etc. Further work will concern the validation of jack actuators and rollers motion models. These models will be validated with users and wheelchair driving experts so that they are realistic both in value and immersion feeling.

\section{ACKNOWLEDGMENT}

We thank the Ile-De-France region, which helped finance the AccesSim project as well as all project partners: EDF R\&D (project leader), LISV (UVSQ), LAMPA (Arts \& Métiers ParisTech), CEREMH and CEA-LIST.

\section{REFERENCES}

[1] F. Goncalves, Conception d'un environnement virtuel avec adaptation de l'immersion pour la simulation de conduit en fauteuil roulant, PhD thesis, 2014 (147 p).

[2] F. Goncalves, L. Trenoras, E. Monacelli, A. Schmid. Motion adaptation on a wheelchair driving simulator. In Virtual and Augmented Assistive Technology (VAAT), 2014, $2^{\text {nd }}$ Workshop on (p.17-22), IEEE.

[3] A. Berthoz \& al., Motion scaling for high-performance driving simulators. Human-Machine Systems, IEEE Transactions on, 43(3):265-276, 2013.

[4] P. R. Grant, M. Blommer, B. Artz, and J. Greenberg. Analysing classes of motion drive algorithms based on paired comparison techniques. Vehicle System Dynamics, 47(9):1075-1093, 2009

[5] P. Archambault, F. Routhier, M. Hamel, and P. Boissy. Analysis of movement to develop a virtual reality poweredwheelchair simulator. In Virtual Rehabilitation, pages 133138, 2008

[6] A. Harrison, G. Derwent, A. Enticknap, F. Rose, and E. Attree. The role of virtual reality technology in the assessment and training of inexperienced powered wheelchair users. Disability \& Rehabilitation, 24(11-12):599-606, 2002

[7] R. A. Cooper, D. M. Spaeth, D. K. Jones, M. L. Boninger, S. G. Fitzgerald, and S. Guo. Comparison of virtual and real electric powered wheelchair driving using a position sensing joystick and an isometric joystick. Medical engineering \& physics, 24(10):703-708, 2002. 